\title{
Construção e validação do instrumento de avaliação do desempenho técnico-tático no voleibol
}

\author{
Construction and validation of a technical-tactical \\ performance evaluation instrument in volleyball
}

\author{
Carine Collet \\ Juarez Vieira do Nascimento \\ Valmor Ramos \\ Joice Mara Facco Stefanello ${ }^{3}$
}

1. Universidade Federal de Santa Catarina. Programa de Pós-Graduação em Educação Física. Florianópolis, SC. Brasil.

2. Universidade do Estado de Santa Catarina. Centro de Ciências da Saúde e do Esporte. Florianópolis, SC. Brasil.

3. Universidade Federal do Paraná. Programa de Pós-Graduação em Educação Física. Curitiba, PR. Brasil.

Recebido em 16/05/10 Revisado em 30/07/10 Aprovado em 15/09/10
Resumo - O objetivo do estudo foi construir e validar o Instrumento de Avaliação do Desempenho Técnico-tático do Voleibol (IAD-VB). A construção dos indicadores de observação baseou-se na consulta à literatura e em modelos de avaliação já existentes. $\mathrm{O}$ processo de validação de conteúdo foi realizado por 10 especialistas da área, nas dimensões da clareza de linguagem, pertinência prática e relevância teórica. Foi realizada a testagem da fidedignidade intra-avaliador (método teste-reteste) e interavaliador (6 avaliadores). A coleta dos dados concentrou-se nas análises em vídeo de jogos de uma equipe finalista do Campeonato Catarinense Infantil de Voleibol 2009. Os dados foram analisados estatisticamente no programa SPSS for Windows, versão 11.5 e no programa SAS, com nível de significância de 5\%. Utilizaram-se o coeficiente de correlação de Spearman, o índice de concordância Kappa ponderado e o índice de correlação intraclasse na análise estatística de cada ação específica de jogo e em cada componente do desempenho. De maneira geral, o IAD-VB compreende um instrumento que avalia as componentes do desempenho técnico-tático das ações de jogo de voleibol 6x6, permitindo a identificação do nível de desempenho geral do jogador, bem como o desempenho específico por ação e por componente. Além disso, o instrumento obteve índices de validade de 92,9\%, e de fidedignidade intra-avaliador de 0,84 e interavaliadores de 0,78 . Todos os índices foram considerados altos, indicando que o IAD-VB compreende um instrumento de observação válido e consistente, bem como possibilita a avaliação do nível do desempenho esportivo de jogadores de voleibol das categorias de formação.

Palavras-chave: Voleibol; Avaliação de desempenho; Desempenho atlético.

Abstract - The aim of this study was to develop and validate a technical-tactical performance evaluation instrument in volleyball (PEI-VB). Observation indicators were constructed based on the literature and on already established evaluation models. Content validation was performed by 10 experts in the field for the dimensions of clarity of language, practical relevance and theoretical relevance. Intra-examiner (test-retest method) and inter-examiner (6 examiners) reliability was tested. Data collection consisted of the analysis of a video of games from the finalist team of the 2009 Catarinense Children's Volleyball Championship. Data were analyzed using the SPSS for Windows 11.5 and SAS programs, with the level of significance set at $5 \%$. Spearman's correlation coefficient, weighted kappa index of agreement, and intraclass correlation coefficient were used for the analysis of each specific action of the game and each performance component. The PEI$-V B$ comprises an instrument that evaluates the components of technical-tactical performance of the actions of a $6 \times 6$ volleyball game, permitting the identification of the general performance level of each player, as well as the specific performance according to action and component. In addition, the validity of the instrument was $92.9 \%$ and the intra- and inter-examiner reliability was 0.84 and 0.78 , respectively. All indices were high, indicating that the PEI-VB is a valid and consistent instrument that permits the evaluation of the level of sports performance of volleyball players of different categories.

Key words: Volleyball; Performance evaluation; Athletic performance. 


\section{INTRODUÇÃO}

A relevância da investigação acerca da evolução do desempenho técnico-tático nos esportes coletivos está associada à necessidade de avaliação do progresso dos jogadores, levando em consideração o processo formativo e de aperfeiçoamento das habilidades e capacidades necessárias à prática da modalidade. $\mathrm{O}$ andamento do ensino, no que tange a evolução esportiva, deve ter como base a identificação do nível de desempenho dos praticantes, para então determinar as etapas da aprendizagem a serem abordadas ${ }^{1}$. Com a realização de avaliações periódicas dos jogadores, o treinador pode julgar o quanto seu método de condução do processo de ensino-aprendizagem-treinamento está surtindo os efeitos desejados e, a partir daí, segui-lo ou alterá-lo conforme as necessidades de sua equipe. Assim, o valor prático da análise do desempenho deve permitir aos treinadores identificar as razões das boas ou más atuações de jogadores e das equipes, bem como compará-las entre si ${ }^{2}$.

Os indicadores presentes na avaliação do desempenho técnico-tático devem focalizar nos aspectos gerais do jogo, na técnica e na tática, o que contribuirá para o entendimento das demandas fisiológicas, psicológicas, técnicas e táticas de muitos esportes ${ }^{3}$. A avaliação realizada pela maioria dos treinadores está baseada na intuição, a partir de análises subjetivas dos jogadores e das equipes, tornando os dados imprecisos e rudimentares ${ }^{2}$, e nem sempre revelando resultados coerentes.

Nas últimas décadas, constata-se um aumento no enfoque das investigações acerca da avaliação do desempenho esportivo nas modalidades esportivas coletivas. Entretanto, a ênfase concentra-se nos componentes físico (testes medindo o desempenho das capacidades físicas) e técnico (avalia o resultado obtido com a execução das habilidades). Com relação ao voleibol, a maioria dos estudos ${ }^{4-10}$ concentra a avaliação do desempenho na eficácia dos jogadores nas ações técnico-táticas do jogo. Poucos são os instrumentos ${ }^{11-14}$ que procuram avaliar, de modo conjunto, as componentes individuais e de compreensão tática dos jogadores.

Ao considerar as características estruturais e as especificidades do voleibol ${ }^{15}$, os instrumentos de avaliação utilizados nesta modalidade necessitam contemplar os principais componentes do desempenho esportivo ${ }^{11,13,14,16}$, relacionados com a compreensão tática (tomadas de decisão, ações de apoio - ajustamento) e com os componentes individuais (execução da habilidade). Além disso, a avaliação específica das ações de jogo permite identificar as potencialidades e possíveis deficiências dos jogadores, auxiliando também na determinação da especialização de funções e posições em quadra durante o jogo.

Nessa perspectiva, o presente estudo teve como objetivo construir e validar um instrumento de avaliação do nível de desempenho técnico-tático (IAD-VB) de jogadores de voleibol das categorias de formação. Para tanto, foi necessário estabelecer os indicadores de avaliação das ações técnico-táticas (fundamentos) do voleibol, considerando os componentes do desempenho técnico-tático, estabelecer os critérios de pontuação, bem como verificar a validade e a fidedignidade do instrumento aplicado em jogadoras da categoria infantil.

\section{PROCEDIMENTOS METODOLÓGICOS}

\section{Instrumento de observação}

$\mathrm{O}$ instrumento elaborado foi composto pelos indicadores de observação de cada ação técnico-tática (saque, recepção, levantamento, ataque, bloqueio e defesa) relacionados aos componentes do desempenho técnico-tático (eficiência, eficácia, tomada de decisão e ajustamento). Além disso, foram determinados os critérios de pontuação de cada indicador e as equações para determinação do nível de desempenho, a serem utilizados durante a aplicação do instrumento.

\section{Testagem do instrumento}

A testagem do instrumento realizou-se por meio da observação em vídeo de jogos de voleibol de equipes masculinas e femininas das categorias mirim, infantil e infanto-juvenil, a fim de assegurar que os indicadores de avaliação fossem representativos das ações observadas em categorias distintas do voleibol. Os dados apresentados referem-se à análise de uma equipe finalista do campeonato estadual infantil feminino, justificada pela similaridade dos dados encontrados nas avaliações realizadas nas 3 categorias. A escolha da equipe foi intencional, tendo em vista a participação nos jogos da fase final do campeonato, bem como pela acessibilidade e permissão de captura de imagens pelo dirigente do clube. Foram tomados todos os cuidados éticos para a captura das imagens, nomeadamente pela aprovação do projeto pelo CEPSH/UFSC (Parecer n ${ }^{\circ} 125 / 08$ ), bem como com a assinatura do TCLE por parte dos pais/responsáveis e treinadores de todas as equipes.

Inicialmente, os indicadores de observação foram determinados a partir da consulta a literatura 
especializada ${ }^{13,15,17,18}$ e baseado em instrumentos de avaliação do desempenho já existentes (GPAI ${ }^{14}$, TSAP ${ }^{11}$ e GPAI/Voleibol ${ }^{13}$ ). Na sequência, realizou-se o processo de validação de conteúdo por 10 especialistas da área, tanto pesquisadores como treinadores com experiência na modalidade, que avaliaram os indicadores nas dimensões da clareza de linguagem, pertinência prática e relevância teórica, determinando o nível de adequação de cada indicador (escala Likert de 1 a 5).

Após a validação de conteúdo, o instrumento passou pela verificação da fidedignidade intra e interavaliadores. A fidedignidade intra-avaliador foi realizada pelo método teste-reteste, com intervalo de duas semanas entre as aplicações. $O$ nível de fidedignidade interavaliadores foi verificado por 6 avaliadores de forma individual, os quais observaram as ações técnico-táticas de uma jogadora em situação real de jogo.

\section{Análise dos dados}

Os dados da validação de conteúdo foram agrupados e analisados com base no percentual de aceitação específica e geral das ações, componentes e indicadores do instrumento. Os indicadores do instrumento foram considerados válidos quando apresentavam índices maiores ou igual a $80 \%{ }^{19}$. Os índices da correlação de Spearman foram classificados em correlação fraca $(0,20$ a 0,40), moderada $(0,40$ a 0,60$)$ e forte (valores acima de 0,60$)^{20}$. Os índices de concordância Kappa foram classificados em concordância ruim (valores inferiores a 0,20), fraca $(0,21$ a 0,40$)$, moderada $(0,41$ a 0,60$)$, boa $(0,61$ a 0,80$)$ e concordância excelente $(0,81$ a $1,0)^{21}$. Todos os dados obtidos foram cadastrados em planilhas de cálculo Excel (Windows XP) e analisados estatisticamente no programa SPSS for Windows, versão 11.5 e no programa SAS. O nível de significância utilizado foi de 5\%.

\section{RESULTADOS}

Instrumento de Avaliação do Desempenho Técnico-tático no Voleibol (IAD-VB)

A avaliação de cada uma das ações técnico-táticas do voleibol, utilizando o IAD-VB, é feita por meio de três indicadores específicos, dependendo do componente a ser avaliado (Quadro 1). Na determinação do nível de desempenho geral dos jogadores, deve-se utilizar a análise de todos os componentes do instrumento. Todavia, quando o objetivo for de analisar somente um dos componentes, ou somente uma ou algumas das ações, o instrumento pode fornecer boas informações acerca da identificação do nível de desempenho específico do jogador.

\section{Critérios de Pontuação e Classificação do Nível de Desempenho}

Ao final da construção do instrumento, foram determinados os critérios de pontuação de cada indicador, considerando-se as diferenças de características de cada componente (Quadro 2).

$\bigcirc$ nível de desempenho dos jogadores corresponde ao somatório de pontos obtidos pelo jogador, durante a avaliação. Com a aplicação do instrumento, podem ser estabelecidos os níveis de Desempenho Específico por Ação (DEA), os níveis de Desempenho Específico por Componente (DEC), e o nível de Desempenho Geral (DEG) do jogador. O DEA é determinado pela equação:

$$
\operatorname{DEA}(\%)=\frac{25(x-4 z)}{3(z)-z}
$$

Onde $\mathbf{x}$ corresponde ao total de pontos obtidos por ação (soma dos componentes de cada ação específica realizada), e $\mathbf{z}$ corresponde ao número de ações específicas avaliadas.

\section{O DEC é determinado pela equação:}

$$
\operatorname{DEC}(\%)=\frac{100(y-z)}{3(z)-z}
$$

Onde y corresponde ao total de pontos obtidos por componente (soma das ações de cada componente), e $\mathbf{z}$ corresponde ao total de ações avaliadas.

As equações foram determinadas com base na ponderação entre os valores mínimos e máximos que o jogador pode obter em determinada ação de jogo (DEA) ou determinado componente (DEC).

O DEG é determinado pelo cálculo da média aritmética do desempenho específico em cada ação, ou pela média aritmética do desempenho específico em cada componente. A classificação do nível de desempenho dos jogadores, correspondente ao resultado obtido no DEA, DEC ou DEG, é classificado como inadequado ( 0 a 33,3\%), intermediário $(33,4 \%$ a $66,6 \%)$ ou adequado $(66,7 \%$ a $100 \%)$.

\section{Processo de Validação de Conteúdo}

A validação de conteúdo do IAD-VB apresentou índice geral de 92,9\% de validade, considerando-se um instrumento válido e aplicável. Quando observados os dados de cada item, constatou-se que todos obtiveram índices acima de 85\%, considerados satisfatórios (Tabela 1).

Os dados da Tabela 1 mostram que a eficiência $(97,3 \%)$ e a eficácia $(95,1 \%)$ foram os componentes que apresentaram maiores índices de validade. Em contrapartida, as avaliações do ajustamento e 
Quadro 1. Indicadores de observação do Instrumento de Avaliação do Desempenho Técnico-tático no Voleibol

\begin{tabular}{|c|c|c|}
\hline Ação & Componente & Indicadores \\
\hline \multirow{4}{*}{$\underset{\substack{0 \\
\frac{0}{2}}}{\stackrel{0}{\sim}}$} & Ajustamento & $\begin{array}{l}\text { AS1: orienta os apoios para o alvo, posicionando o corpo na direção em que pretende sacar; } \\
\text { AS2: depois de sacar, desloca-se rapidamente para ocupar o espaço na defesa; } \\
\text { AS3: depois de sacar, coloca-se na defesa na posição de expectativa (pernas afastadas, joelhos } \\
\text { semi-flexionados, tronco inclinado à frente). }\end{array}$ \\
\hline & Eficiência & $\begin{array}{l}\text { EFS1: coloca o pé contrário do membro superior dominante à frente no momento de bater a bola; } \\
\text { EFS2: lança a bola com o membro superior não dominante na altura adequada à frente do eixo do } \\
\text { corpo; } \\
\text { EFS3: bate a bola com o membro superior dominante em extensão. }\end{array}$ \\
\hline & $\begin{array}{c}\text { Tomada } \\
\text { de decisão }\end{array}$ & $\begin{array}{l}\text { TDS1: coloca a bola em jogo; } \\
\text { TDS2: direciona a bola para determinado jogador (tática coletiva); } \\
\text { TDS3: direciona a bola no espaço livre ou entre dois jogadores ou saca com a máxima potência. }\end{array}$ \\
\hline & Eficácia & $\begin{array}{l}\text { S1: erro de saque; } \\
\text { S2: continuidade da ação pela equipe adversária; } \\
\text { S3: ponto. }\end{array}$ \\
\hline \multirow{2}{*}{ 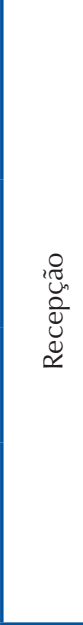 } & Eficiência & $\begin{array}{l}\text { EFR1: membros inferiores semiflexionados e apoiados no chão no momento do contato; } \\
\text { EFR2: posiciona o corpo atrás da bola e contata a bola no meio dos apoios; } \\
\text { EFR3: contata a bola na plataforma formada pelos antebraços com os membros superiores em } \\
\text { extensão (manchete) ou contata a bola acima e à frente do nível da testa (toque). }\end{array}$ \\
\hline & $\begin{array}{l}\text { Tomada de } \\
\text { decisão }\end{array}$ & $\begin{array}{l}\text { TDR1: envia a bola diretamente à quadra adversária; } \\
\text { TDR2: mantém a bola em jogo na própria equipe, porém sem direcionamento (coloca a bola para cima); } \\
\text { TDR3: antecipa-se e direciona a bola para a zona de levantamento. }\end{array}$ \\
\hline \multirow{3}{*}{ 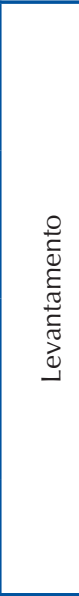 } & Eficiência & $\begin{array}{l}\text { EFL1: contata a bola na plataforma formada pelos antebraços com os membros superiores em } \\
\text { extensão (manchete) ou contata a bola acima e à frente do nível da testa (toque); } \\
\text { EFL2: coordena a flexão e extensão dos membros superiores e inferiores; } \\
\text { EFL3: no momento do contato, orienta a posição corporal para a zona de finalização do ataque. }\end{array}$ \\
\hline & $\begin{array}{c}\text { Tomada } \\
\text { de decisão }\end{array}$ & $\begin{array}{l}\text { TDL1: mantém a bola em jogo na própria equipe, porém sem direcionamento (coloca a bola para cima); } \\
\text { TDL2: imprime força e direcionamento adequado para que a bola chegue ao jogador que realiza } \\
\text { o ataque; } \\
\text { TDL3: coloca a bola no jogador que está mais bem posicionado e com bloqueio mais baixo ou o } \\
\text { melhor jogador da equipe (maior pontuador). }\end{array}$ \\
\hline & Eficácia & $\begin{array}{l}\text { L1: erro de levantamento; } \\
\text { L2: continuidade da ação pela própria equipe; } \\
\text { L3: proporciona o ataque sem bloqueio ou com bloqueio simples ou quebrado. }\end{array}$ \\
\hline \multirow[b]{2}{*}{$\frac{0}{\frac{0}{2}}$} & Ajustamento & $\begin{array}{l}\text { AA1: aguarda a realização do levantamento para iniciar a corrida de aproximação (vai para o } \\
\text { ponto de partida de ataque); } \\
\text { AA2: adéqua a chamada de ataque de acordo com a trajetória e velocidade do levantamento; } \\
\text { AA3: ajusta a velocidade do movimento do braço de ataque em função do bloqueio adversário. }\end{array}$ \\
\hline & Eficiência & $\begin{array}{l}\text { EFA1: posiciona o pé contrário do membro superior dominante ligeiramente à frente; } \\
\text { EFA2: coordena a flexão e extensão dos membros inferiores com o pêndulo dos membros supe- } \\
\text { riores; } \\
\text { EFA3: aborda a bola acima e à frente do corpo com o braço dominante estendido no momento do } \\
\text { contato com a bola, ou contata a bola na plataforma formada pelos antebraços com os membros } \\
\text { superiores em extensão (manchete), ou contata a bola acima e à frente do nível da testa (toque) }\end{array}$ \\
\hline
\end{tabular}




\begin{tabular}{|c|c|c|}
\hline \multirow{4}{*}{$\frac{\frac{0}{0}}{\frac{0}{0}} \frac{0}{\infty}$} & Ajustamento & $\begin{array}{l}\text { AB1: adota a posição corporal com os braços levantados próximo à rede no momento do saque } \\
\text { da própria equipe ou do primeiro toque da equipe adversária; } \\
\text { AB2: ajusta a posição corporal de acordo com a trajetória da bola e ao braço de ataque do adver- } \\
\text { sário; } \\
\text { AB3: desloca-se rapidamente e ajusta o tempo de salto com a velocidade e altura da execução do } \\
\text { ataque. }\end{array}$ \\
\hline & Eficiência & $\begin{array}{l}\text { EFB1: coordena a flexão e extensão dos membros inferiores com a extensão dos membros supe- } \\
\text { riores; } \\
\text { EFB2: durante a fase aérea, os membros superiores invadem o espaço aéreo adversário; } \\
\text { EFB3: retorna ao solo em equilíbrio. }\end{array}$ \\
\hline & $\begin{array}{l}\text { Tomada de } \\
\text { decisão }\end{array}$ & $\begin{array}{l}\text { TDB1: não efetua bloqueio na sua zona de responsabilidade; } \\
\text { TDB2: efetua bloqueio defensivo; } \\
\text { TDB3: antecipa a ação do levantamento do adversário e efetua bloqueio ofensivo. }\end{array}$ \\
\hline & Eficácia & $\begin{array}{l}\text { B1: erro de bloqueio (toque na rede, bloqueio para fora, etc.); } \\
\text { B2: continuidade da ação pela própria equipe ou pela equipe adversária; } \\
\text { B3: ponto. }\end{array}$ \\
\hline \multirow{4}{*}{ 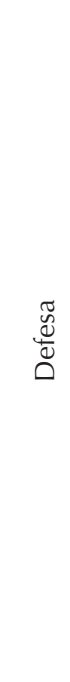 } & Ajustamento & $\begin{array}{l}\text { AD3: desloca-se para local provável de queda da bola (antecipação) em função da ação do ataque } \\
\text { adversário; } \\
\text { AD2: ajusta a posição corporal na zona de responsabilidade que ocupa em função da formação } \\
\text { do bloqueio; } \\
\text { AD1: ajusta a sua posição em função da proximidade das linhas laterais (pé esquerdo à frente } \\
\text { quando estiver mais próximo da linha à sua esquerda ou pé direito à frente quando estiver mais } \\
\text { próximo da linha à sua direita) antes do contato. }\end{array}$ \\
\hline & Eficiência & $\begin{array}{l}\text { EFD1: membros inferiores semiflexionados e apoiados no chão, no momento do contato; } \\
\text { EFD2: posiciona o corpo atrás da bola e contata a bola no meio dos apoios; } \\
\text { EFD3: contata a bola na plataforma formada pelos antebraços com os membros superiores em } \\
\text { extensão (manchete), ou contata a bola acima e à frente do nível da testa (toque). }\end{array}$ \\
\hline & $\begin{array}{l}\text { Tomada de } \\
\text { decisão }\end{array}$ & $\begin{array}{l}\text { TDD1: defende a bola e envia diretamente para a quadra adversária; } \\
\text { TDD2: mantém a bola em jogo na própria equipe, porém sem direcionamento (coloca a bola para } \\
\text { cima); } \\
\text { TDD3: imprime força e o direcionamento adequado para que a bola chegue à zona de levanta- } \\
\text { mento. }\end{array}$ \\
\hline & Eficácia & $\begin{array}{l}\text { D1: erro de defesa; } \\
\text { D2: continuidade da ação pela equipe adversária; } \\
\text { D3: continuidade da ação pela própria equipe. }\end{array}$ \\
\hline
\end{tabular}

Quadro 2. Critérios de pontuação estabelecidos para o Instrumento de Avaliação do Desempenho Técnico-tático no Voleibol

\begin{tabular}{|l|c|c|}
\hline Componente & Característica & Critérios de pontuação \\
\hline \multirow{2}{*}{$\begin{array}{l}\text { Ajustamento / } \\
\text { Eficiência }\end{array}$} & \multirow{3}{*}{ Complementaridade } & 1 ponto: Realiza nenhum ou somente 1 item \\
\cline { 3 - 3 } & & 2 pontos: Realiza 2 itens \\
\hline \multirow{2}{*}{$\begin{array}{l}\text { Tomada de decisão / } \\
\text { Eficácia }\end{array}$} & \multirow{3}{*}{ Contraposição } & 1 ponto: S1, R1, L1, A1, B1 e D1 \\
\cline { 3 - 3 } & & 2 pontos: S2, R2, L2, A2, B2 e D2 \\
\cline { 3 - 3 } & & 3 pontos: S3, R3, L3, A3, B3 e D3 \\
\hline
\end{tabular}

Tabela 1. Percentual médio da avaliação dos especialistas por componente, considerando todas as ações de jogo.

\begin{tabular}{lccccc}
\hline $\begin{array}{l}\text { Componente/ } \\
\text { Ação }\end{array}$ & Ajustamento & Eficiência* & Tomada de decisão & Eficácia & Geral \\
\hline Saque & $85,8 \%$ & $96,3 \%$ & $90,8 \%$ & $92,8 \%$ & $91,4 \%$ \\
Recepção & $91,7 \%$ & $98,1 \%$ & $85 \%$ & $92,5 \%$ & $91,8 \%$ \\
Levantamento & $92,2 \%$ & $97,5 \%$ & $91,9 \%$ & $89,4 \%$ & $92,8 \%$ \\
Ataque & $87,2 \%$ & $95,4 \%$ & $91,1 \%$ & $98,9 \%$ & $93 \%$ \\
Bloqueio & $92,2 \%$ & $99,1 \%$ & $90,5 \%$ & $99,4 \%$ & $95,3 \%$ \\
Defesa & $90,8 \%$ & $97,2 \%$ & $86,4 \%$ & $97,2 \%$ & $92,9 \%$ \\
Geral & $90 \%$ & $97,3 \%$ & $89,3 \%$ & $95,1 \%$ & $92,9 \%$ \\
\hline
\end{tabular}

*os dados da eficiência correspondem à avaliação de 9 especialistas. 
da tomada de decisão obtiveram índices em torno de $90 \%$, apresentando os menores valores quando comparados aos demais.

Os valores relacionados aos indicadores do saque $(91,4 \%)$ e da recepção $(91,8 \%)$ obtiveram índices de aceitação similares, com valores mais baixos apresentados nos componentes ajustamento $(85,8 \%)$ e tomada de decisão $(85 \%)$, respectivamente. Os indicadores de observação das ações de levantamento (92,8\%), ataque (93\%) e defesa (92,9\%) também obtiveram índices similares, sendo que, no levantamento, os valores mais elevados foram observados na eficiência (97,5\%). Nas ações de ataque e defesa, os valores mais elevados estavam relacionados aos componentes da eficiência e eficácia e os mais baixos ao ajustamento e a tomada de decisão. A ação de bloqueio obteve índice de validação mais elevado (95,3\%), o qual foi considerado altamente adequado aos indicadores correspondentes à eficiência $(99,1 \%)$ e à eficácia $(99,4 \%)$.

\section{Fidedignidade Intra-avaliador}

Na obtenção do grau de fidedignidade intra-avaliador, foram realizadas 120 avaliações, sendo 5 situações de cada ação de jogo, envolvendo os 4 componentes em cada ação. Desse total, 109 avaliações foram iguais $(90,8 \%)$ e 11 diferentes $(9,2 \%)$, principalmente no que diz respeito ao ajustamento e à tomada de decisão das ações de recepção e defesa.

Os dados da Tabela 2 demonstram que, de maneira geral, o instrumento obteve $90,8 \%$ de concordância bruta, com índice Kappa de 0,84 e coeficiente de correlação de 0,86 , ambos considerados excelentes ${ }^{20,21}$.

Todas as ações de levantamento e ataque obtiveram avaliações iguais em todos os componentes, quando comparados o teste e o reteste, obtendo índices de correlação iguais a 1. As ações de saque e bloqueio obtiveram altos índices de correlação, ambos em torno de 0,90. Nas 20 ações avaliadas de saque, 18 foram avaliadas de forma idêntica, com o índice de correlação de Spearman de 0,91 e o índice de concordância Kappa de 0,84. As ações de recepção e defesa obtiveram menores índices de correlação (0,69 e 0,70, respectivamente), embora ainda pertençam ao nível considerado como forte correlação ${ }^{20}$. Na defesa, o índice de concordância 0,57 estimado pelo índice Kappa foi considerado moderado ${ }^{21}$, em que foram observadas 5 diferenças no total de 20 avaliações dessa ação.

\section{Fidedignidade Interavaliador}

Os dados relacionados à fidedignidade interavaliador demonstraram graus satisfatórios de estabilidade, pois a estimativa geral da correlação intraclasse

Tabela 2. Frequência de concordância e índices de correlação do instrumento.

\begin{tabular}{|c|c|c|c|c|c|c|c|}
\hline & Ajustamento & Eficiência & Tomada de decisão & Eficácia & Total & Spearman & Карра \\
\hline Recepção & $4 / 5$ & $4 / 5$ & $4 / 5$ & $5 / 5$ & $17 / 20$ & $0,69^{*}$ & $0,68^{*}$ \\
\hline Levantamento & $5 / 5$ & $5 / 5$ & $5 / 5$ & $5 / 5$ & $20 / 20$ & $1 *$ & $1 *$ \\
\hline Ataque & $5 / 5$ & $5 / 5$ & $5 / 5$ & $5 / 5$ & $20 / 20$ & $1^{*}$ & $1^{*}$ \\
\hline Defesa & $2 / 5$ & $4 / 5$ & $4 / 5$ & $5 / 5$ & $15 / 20$ & $0,70^{*}$ & $0,57^{*}$ \\
\hline Total & $26 / 30$ & $28 / 30$ & $25 / 30$ & $30 / 30$ & $109 / 120$ & 0,86 & 0,84 \\
\hline Spearman & 0,72 & 0,93 & 0,76 & 1 & 0,86 & - & - \\
\hline Карра & 0,71 & 0,90 & 0,74 & 1 & 0,84 & - & - \\
\hline
\end{tabular}

${ }^{*} p<0,001$.

Tabela 3. Índices de correlação geral entre os avaliadores.

\begin{tabular}{clllll}
\hline Avaliadores & 1 & 2 & 3 & 4 & 5 \\
\hline 1 & & & & \\
2 & $0,81^{*}$ & & & \\
3 & $0,77^{*}$ & $0,74^{*}$ & & \\
4 & $0,81^{*}$ & $0,76^{*}$ & $0,84^{*}$ & & \\
5 & $0,82^{*}$ & $0,76^{*}$ & $0,80^{*}$ & $0,78^{*}$ & $0,79^{*}$ \\
\hline
\end{tabular}

${ }^{*} \mathrm{p}<0,01$. 
revelou forte correlação $(0,78)$ entre as avaliações dos pesquisadores. Os dados da Tabela 3 mostram os índices de correlação de Spearman comparando, conjuntamente, as avaliações dos 6 pesquisadores. Todos os coeficientes de correlação foram considerados fortes ${ }^{20}$, pois variaram de 0,74 a 0,84.

O maior coeficiente de correlação foi observado entre os pesquisadores 3 e 4, os quais apresentaram critérios semelhantes na aplicação do instrumento. Os demais índices foram considerados satisfatórios, revelando que o instrumento possui graus elevados de correlação entre os diferentes avaliadores. $O$ coeficiente mais baixo foi observado entre os avaliadores 2 e 3, pois algumas avaliações do ajustamento foram distintas entre ambos.

\section{DISCUSSÃO}

Os indicadores de observação do IAD-VB foram estabelecidos considerando-se as características dos jogadores das categorias de formação, além de ter a preocupação em respeitar os níveis de exigência de acordo com a categoria. Um indicador de desempenho diz respeito à seleção ou combinação de variáveis da ação, com o objetivo de definir algum ou todos os aspectos do desempenho esportivo ${ }^{3}$. De fato, os indicadores de observação das ações técnico-táticas buscaram contemplar as fases de preparação para a realização das ações ${ }^{22}$ (ajustamento), os pormenores da execução das habilidades do voleibol $^{13}$ (eficiência), as possibilidades de decisão em cada ação ${ }^{23,24}$ (tomada de decisão), bem como os resultados obtidos por meio da execução das habilidades fundamentais do jogo ${ }^{25,16}$ (eficácia).

Os indicadores de observação do saque buscaram atender aos elementos que compreendem as quatro fases principais da ação: posição inicial, lançamento da bola, ataque à bola e finalização ${ }^{26}$, relacionados com o saque por cima, que propicia maior potência de golpe e, consequentemente, maior velocidade da bola ${ }^{18}$. Em vista disso, a maioria dos jogadores das escolinhas de formação utiliza o saque por cima, visando o êxito, embora o saque por baixo constitua uma execução mais fácil quando se trata de iniciação esportiva.

$\mathrm{Na}$ avaliação da recepção, determinaram-se os indicadores levando em consideração o objetivo de recuperar a bola para a construção do ataque, sendo que a qualidade da execução depende da qualidade do envio da bola (saque) pela equipe adversária ${ }^{7}$. Alguns estudos ${ }^{4,6,18}$ confirmam a importância da qualidade na recepção, pois verificaram uma elevada influência da eficácia da recepção no incremento da ofensividade do ataque da equipe. O estabelecimento do local adequado para o envio da bola vai depender da identificação inicial do sistema de jogo adotado pela equipe, tendo em vista as possíveis diferenças de local e altura do envio da bola, específicos de cada equipe.

A avaliação do levantamento buscou contemplar os principais elementos da ação, considerando as condições ideais para realizar o levantamento. As ações do levantador se constituem como peças-chave de qualquer equipe, pois a maioria das ações ofensivas passa pelas mãos do levantador. A ação do levantamento deve ser executada com agilidade, observando seus próprios atacantes e os jogadores adversários, procurando identificar os pontos mais fracos do bloqueio e da defesa adversária para facilitar um ataque mais eficaz $z^{7,10}$.

$\mathrm{Na}$ avaliação do ataque, também foram determinados os indicadores relacionados ao ajustamento, eficiência, tomada de decisão e eficácia. Considera-se ataque quando o jogador devolve a bola para o campo adversário, com qualquer técni$\mathrm{ca}^{7,27}$ ou gesto técnico, buscando a finalização ${ }^{28}$. A cortada é o fundamento que finaliza a maioria das ações ofensivas e visa enviar, através de um golpe forte dado durante um salto, a bola de encontro ao solo da quadra do adversário ${ }^{17}$. $\mathrm{O}$ ataque é a ação mais expressiva do voleibol e a que possui papel decisivo na situação ofensiva de uma equipe ${ }^{7,18}$, pois geralmente é a ação que gera maior número de pontos para a equipe.

Os indicadores da avaliação do bloqueio correspondem à ação dos jogadores próximos à rede, os quais têm o objetivo de interceptar a bola após o ataque adversário. A execução correta do bloqueio permite aos jogadores ter maiores possibilidades de êxito na obtenção do ponto direto para sua equipe, ou para atenuar a força do ataque adversário para a realização da defesa. Além disso, para avaliar o bloqueio, é preciso considerar o posicionamento do jogador em quadra, contextualizando as suas responsabilidades na ação $0^{23,24}$.

$\mathrm{Na}$ avaliação da defesa, determinaram-se os indicadores relacionados às características desta ação técnico-tática. A ação da defesa possui objetivos semelhantes aos da recepção, evitando que a bola caia sobre o solo e visando a construção do contra-ataque, embora o intervalo de tempo disponível para a ação seja reduzido ${ }^{7,27}$. Apesar de os indicadores da defesa serem similares aos da recepção, visto que se trata do primeiro toque da equipe após a ação da equipe adversária, torna-se importante considerar a diferença de intervalo 
entre as últimas ações do adversário (saque ou ataque) e as primeiras da equipe (recepção ou defesa). Com relação à recepção, a trajetória que a bola percorre após a ação do saque é maior do que após o ataque, tornando a defesa mais exigente em termos de velocidade e agilidade.

Os critérios de pontuação estabelecidos para cada componente correspondem às diferentes características de contraposição e complementaridade dos indicadores. Assim como no presente estudo, foi identificado um estudo ${ }^{26}$ que traz uma escala ordinal ou qualitativa com atribuição de valores (os intervalos possuem as mesmas dimensões) combinada com uma escala descritiva (descrições concisas e exatas sobre o comportamento observado) ${ }^{26}$.

Com relação aos índices de validade e fidedignidade encontrados no estudo, observou-se que os maiores valores encontrados nos componentes eficiência e eficácia devem-se à maior facilidade em visualizar e identificar a execução técnica nas ações dos jogadores, bem como o resultado da ação. Além disso, os altos índices encontrados nos indicadores correspondentes a tais componentes confirmaram a elevada adequação do instrumento com os elementos apresentados pela literatura ${ }^{6,13,17,18}$. Em contrapartida, os indicadores relacionados com o ajustamento e a tomada de decisão foram os que obtiveram menores índices, pois possuem características cognitivas que tornam mais dificultada a avaliação objetiva, dando oportunidades às diferentes interpretações. Tal fato pode ser explicado pela maior dificuldade em avaliar estes componentes por meio da percepção na ação ${ }^{29}$, além da dificuldade intrínseca do teste psicométrico em neutralizar as interpretações pessoais na aplicação de um instrumento de observação do comportamento ${ }^{30}$.

De maneira geral, a avaliação dos especialistas acerca dos indicadores de cada ação demonstrou índices altamente válidos ${ }^{19}$, considerando que os elementos utilizados para a descrição e definição dos indicadores eram possíveis de observação durante as situações de jogo. Os valores obtidos na fidedignidade intra-avaliador foram semelhantes aos encontrados em estudo ${ }^{13}$ que realizou uma adaptação do instrumento GPAI para o voleibol, o qual obteve concordância de $89 \%$, determinado por meio do teste Kappa. Na fidedignidade interavaliadores, os índices mais baixos foram encontrados no ajustamento da defesa, em virtude da maior dificuldade de leitura do contexto de jogo e da interpretação do local ideal em que deveria estar cada jogador. Em vista disso, alguns indicadores da defesa foram reestruturados, a fim de melhorar a descrição e possibilitar uma observação mais objetiva, assim como nos demais indicadores que apresentaram dificuldades de observação.

\section{CONCLUSÕES}

A principal finalidade do IAD-VB é identificar e avaliar o nível de desempenho técnico-tático dos jogadores das categorias de formação do voleibol, tendo em vista os diferentes componentes e as ações realizadas, durante o envolvimento com as situações de jogo. Após o estabelecimento dos indicadores do instrumento e dos testes realizados, pôde-se concluir que, de maneira geral, o instrumento mostrou-se cientificamente válido e utilizável no âmbito da pesquisa e nas situações da prática profissional.

Os componentes da dimensão técnica (eficiência e eficácia), por apresentarem elementos mais facilmente observáveis, os quais se relacionam com as ações motoras e os resultados de cada ação, obtiveram maiores índices de validade e fidedignidade intra e interavaliador. Em contrapartida, os componentes da dimensão tática (ajustamento e tomada de decisão) apresentaram menores índices, devido à característica cognitiva e adaptativa ao contexto do jogo, tornando a avaliação um pouco mais subjetiva, embora os valores encontrados tenham revelado fortes correlações e concordâncias excelentes. As diferenças encontradas nas avaliações estavam relacionadas com a interpretação das situações e contextos apresentados no jogo, ou seja, com a avaliação da qualidade do envio da bola pela equipe adversária, para então definir as adaptações necessárias aos jogadores para a recuperação da bola. Nesse contexto, todos os indicadores que obtiveram diferenças de avaliações foram revisados e, em alguns casos, modificados, buscando aumentar a objetividade nas observações durante a aplicação do instrumento.

\section{Agradecimentos}

Aos membros do Laboratório de Pedagogia do Esporte (LAPE/UFSC) por todo o apoio, aos especialistas que participaram do processo de validação do instrumento e à CAPES/CNPq, o nosso muito obrigado.

\section{REFERÊNCIAS BIBLIOGRÁFICAS}

1. Mesquita I. Regulação da interferência contextual no ensino das tarefas desportivas. Rev Port Cien Desp 2004:4(2 supl):76-8.

2. Tavares F. Analisar o jogo nos esportes coletivos para melhorar a performance: uma necessidade para o processo de treino. In: Rose Jr D. Modalidades Esportivas Coletivas. Rio de Janeiro: Guanabara Koogan; 2006. p. 60-67. 
3. Hughes MD, Bartlett RM. The use of performance indicators in performance analysis. J Sports Sci 2002;20(10):739-54.

4. Callejón D, Hernández C. Estudio y análisis de la recepción en el voleibol masculino de alto rendimiento. Rev Int Cien Deporte 2009;16(5):34-52.

5. Gouvêa FL, Lopes MBS. Incidência no ataque do voleibol infanto-juvenil feminino. Mov Percepção 2008;9(12):168-83.

6. Maia N, Mesquita, I. Estudo das zonas e eficácia da recepção em função do jogador recebedor no voleibol sênior feminino. Rev Bras Educ Fis Esp 2006;20(4):257-70.

7. Marcelino R, Mesquita I, Sampaio J. Estudo dos indicadores de rendimento em Voleibol masculino em função do número do set. Rev Bras Cien Mov 2008;16(3):1-24.

8. Martín JJM, Campo JAS, Moro MIB, Noguera MAD. Análisis de juego desde el modelo competitivo: un ejemplo aplicado al saque en voleibol. Kronos 2004;5(3):37-45.

9. Moreno MP, García de Alcaraz A, Moreno A, Molina J J, Santos JA. Estudio de la dirección del saque en la superliga masculina de voleibol. Eur J Hum Mov 2007;18:111-34

10. Ramos MHKP, Nascimento JV, Collet C. Avaliação do desenvolvimento das habilidades técnico-táticas em equipes de voleibol infantil masculino. Rev Bras Cineantropom Desempenho Hum 2009;11(2):181-9.

11. Gréhaigne JF, Godbout P, Bouthier D. Performance assessment in team sports. J Teach Phys Educ 1997;16(4):500-16.

12. Mesquita, I. Ensinar bem para aprender melhor o jogo de Voleibol. In. Tani G, Bento J, Petersen R. editores. Pedagogia do Desporto, pp. 327-343. Rio de Janeiro: Guanabara, Koogan. (2006).

13. Mesquita I, Graça A, Gomes AR, Cruz C. Examining the impact of a step game approach to teaching volleyball on student tactical decision making and skill execution during game play. J Hum Mov Stud 2005;48:469-92.

14. Oslin JL, Mitchell SA, Griffin LL. The Game Performance Assessment Instrument (GPAI): Development and Preliminary Validation. J Teach Phys Educ 1998;17(2):231-43.

15. Mesquita I. O ensino do voleibol; uma proposta metodológica. In: Graça A, Oliveira J. O ensino dos jogos desportivos coletivos. Porto: FCDEF-UP; 1998. p. 153-199.

16. Rink J. Teaching physical education for learning. St. Louis: Mosby, 1993.

17. Bojikian JCM. Ensinando Voleibol. Guarulhos: Phorte. 1999.

18. Ugrinowitsch C, Uehara P. Modalidade Esportivas Coletivas: o voleibol. In: Rose Jr D. editor. Modalidades Esportivas Coletivas. Rio de Janeiro: Guanabara Koogan; 2006. p. 166-179.
19. Cassepp-Borges V, Balbinotti MAA, Teodoro MLM Tradução e validação de conteúdo: uma proposta para a adaptação de instrumentos. In: Pasquali L, organizador. Instrumentação Psicológica: fundamentos e práticas. Porto Alegre: Artmed; 2009. p. 506-520.

20. Mitra A, Lanforkd S. Research methods in park, recreation and leisure services. Champaign: Sagamore Publishing, 1999.

21. Landis JR, Koch GG. The measurement of observer agreement for categorical data. Biometrics 1977;33(1):159-74.

22. Tavares F, Faria R. A capacidade de jogo como pré-requisito do rendimento para o jogo. In: Oliveira J, Tavares F, organizadores. Estratégia e tática nos Jogos Desportivos Coletivos. Portugal: Minerva; 1996. p. 39-50.

23. Afonso J, Mesquita I, Marcelino R. Estudo de variáveis especificadoras da tomada de decisão, na organização do ataque, em voleibol feminino. Rev Port Cien Desp 2008;8(1):137-147.

24. Machado AA, Araújo D. Contexto esportivo e as restrições comportamentais: reflexões a luz da Psicologia Bioecológica. Motriz 2010;16(2):432-9.

25. Mesquita I, Marques A, Maia J. A relação entre a eficiência e a eficácia no domínio das habilidades técnicas em Voleibol. Rev Port Cien Desp 2001;1(3):33-9.

26. Meira Jr. CM. Validação de uma lista de checagem para análise qualitativa do saque do voleibol. Motriz 2003;9(3):153-60

27. Mourão PJM, Gonçalves FJM. Avaliação táctica no voleibol: o posicionamento defensivo e zonas vulneráveis em função da zona do ataque adversário no $5^{\circ}$ jogo da fase final do Play-Off Divisão A1. Motricidade 2008;4(4):51-8.

28. Moutinho CAS. A estrutura funcional do voleibol. In: Graça A, Oliveira J. O ensino dos jogos desportivos coletivos. Porto: FCDEF-UP; 1998. p. 137-152.

29. Araújo D. Tomada de decisão no desporto. Cruz Quebrada: Edições FMH. 2006.

30. Pasquali L. Psicometria: teoria dos testes na psicologia e na educação. Petrópolis: Vozes. 2004.

\author{
Endereço para correspondência \\ Carine Collet \\ R: Sebastião Laurentino da Silva, 126, apto 707. \\ Bairro Córrego Grande \\ CEP: 88037-400 - Florianópolis, SC. Brasil \\ E-mail: ca_collet@hotmail.com
}

